\title{
Science and Religion: Two Products of Human Imagination
}

\author{
J. T. Trevors • M. H. Saier Jr.
}

Published online: 15 March 2007

(C) Springer Science + Business Media B.V. 2007

Science and religion share some important characteristics, but in other respects they represent opposites. Science is simply in search of natural explanations using the method of scientific inquiry. It does not insist or state that the supernatural does not exist. The scientific method is based on hypothesis formulation followed by testing, where the test depends on observation, experimentation and evaluation. By contrast, religion uses a system of beliefs that does not require experimentation, predictability, reproducibility or evaluation. A belief system simply requires that one believes. Period! In many religious teachings, to believe without question is considered a virtue. In this respect, science and religion represent two very different approaches to life and its complexities. They depend on different precepts for purportedly understanding our natural world.

Since religion is based on faith while science is based on logical deduction and experimentation, one might ask what these systems could possibly have in

\section{J. T. Trevors}

Department of Environmental Biology,

University of Guelph,

Guelph, ON, Canada N1G 2W1

e-mail: jtrevors@uoguelph.ca

\section{H. Saier Jr. $(\square)$}

Biological Sciences, University of California at San Diego, La Jolla, CA 92093-0116, USA

e-mail: msaier@ucsd.edu common. In fact, science and religion share some powerful characteristics and dependencies, central to all human activities. For example, they both attempt to provide answers to questions such as who we are, where we came from, and what the origins of our world and the universe are.

Another shared characteristic that we would like to focus on in this editorial is the use of imagination. Imagination is essential to many human activities such as business, engineering, science, health, art, and our personal interactions. It has also been instrumental in the design and interpretation of ancient and current belief systems. Imagination provides an initial basis for problem solving. We egocentrically contend that humans are the most imaginative species on Earth, and as far as we know, this is true. If so, we have a remarkable gift which we can exercise and utilize to advantage. But imagination can be used for many purposes - beneficial, detrimental or neutral.

Imagination is central to good science; it is necessary to conceive testable hypotheses and design correct experiments. It allows us to conclude what aspects of the unknown need to be researched. It tells us which experimental approaches can be used to answer specific questions. It guides us as to how data should be interpreted and to what extent speculations might be justified. If we were unable to perceive connections between events and facts that comprise the pieces of a puzzle, our scientific and technological achievements would be much more limited. 
Imagination is also important to religion. In designing metaphysical explanations for the universe, our planet, the biosphere, and their origins, imagination played, and continues to play, a key role. Scriptures reflect the attitudes and values of the people who lived at the time when those scriptures were written. Moreover, interpretations of ancient religious writings are constantly changing in conformity with changes in social attitudes and convention. In fact, many religious doctrines are undergoing continual updates as is true, for example, for the King James translations of the two Christian Testaments. The current translations represent "the culmination of previous translations."

Examples of outdated social practices abound in both the Old and the New Testaments. These have led people who believe these books to reflect the "revealed word of God" to be perplexed about what the right course of action might be. Indeed, the tremendous differences between attitudes professed in these two books (e.g., "an eye for an eye" versus "turn the other cheek" must lead believers to note that God underwent remarkable evolutionary change over a mere 2-3 thousand years. It's interesting that gods apparently evolve much more rapidly than do humans!

A few puzzling examples from the Old Testament that have bothered one (and perhaps many) presentday Christian are enumerated below. This informed US citizen notes and asks:

1. Leviticus 25:44 states that I may possess slaves, both male and female, provided they are purchased from neighboring nations. A friend of mine claims that this applies to Mexicans, but not to Canadians. Can you clarify? Why can't I own Canadians?

2. I would like to sell my daughter into slavery, as sanctioned in Exodus 21:7. In this day and age, what do you think would be a fair price for her (I'm pretty sure she's a virgin)?

3. I have a neighbor who insists on working on the Sabbath. Exodus 35:2 clearly states that he should be put to death. Am I morally obligated to kill him myself, or should I ask the police to do it?

4. A friend of mine feels that even though eating shellfish is an abomination (Lev. 11:10), it is a lesser abomination than homosexuality. I don't agree. Can you settle this? Aren't there 'degrees' of abomination?
5. Lev. 21:20 states that I may not approach the altar of God if I have a defect in my sight. I have to admit that I wear reading glasses. Does my vision have to be $20 / 20$, or is there some wiggle-room here?

6. Most of my male friends get their hair trimmed, including the hair around their temples, even though this is expressly forbidden by Lev. 19:27. How should they die?

7. I know from Lev. 11:6-8 that touching the skin of a dead pig makes me unclean, but may I still play football if I wear gloves?

The point of this short humorous exercise is to note that social values change, and what was once acceptable behavior, as reflected by the scriptures, may now be considered improper or even immoral.

Divisive exercises in imagination account for the segregation of a single religion (e.g., Judaism) into several major religions (e.g., Judaism, Islam and Christianity). It also explains the further subdivision of each of these religions into their various dissenting sects. In this regard it is amazing that without testing, one group can avow that their beliefs are correct while many or all others are wrong. Unfortunately, religious people often justify discriminating against, torturing and killing people who profess beliefs and values other than their own. Moreover, religious dogma often leads people to deny scientific facts altogether.

Dogmatism is not an exclusive characteristic of religion: it is also a common trait in science. Once scientists have "proven" a postulate correct or false, alternatives may no longer be entertained. In fact, our breadth of knowledge, based on previous efforts, serves as our base - our springboard for future advances. Thus, acceptance of established scientific dogma can facilitate progress. Yet dogmatism in science, as in religion, can get one into trouble. It may be rare, but "established" scientific theories can be proven partially or fully incorrect. Because of dogmatism, often expressed as skepticism, there is resistance to change, even when the experimental evidence may be overwhelming. Nevertheless, the new view will eventually emerge, usually dependent on further experimentation. Expansion of the original concepts with greater attention to detail is the usual outcome.

Do all scientists exhibit the quality of dogmatism? The answer, happily, is no. Many of our best scientists recognize the error prone nature of the scientific 
process and remain open to further testing and research. Similarly, not all religions claim exclusivity. Compared to most of the world's other major religions, Buddhism, Confucianism and Taoism turn out to be remarkably tolerant. Belief in the deities of one of these religions does not exclude belief in those of another. Buddhist temples in Taiwan, for example, frequently include shrines and statues representing the deities of the other two principal religions of their state. We refer to these Eastern religions as the "gentle" religions. How much more pleasant and tolerant human societies would be if our primary Western religions were equally accepting of alternative views.

Consider the following question. Is religion and the belief in a supernatural domain purely an exercise in human imagination? Imagination may have created all of the supernatural entities that populate or have ever populated the thousands of religions that have existed since the emergence of human society. The Greeks and Romans had their mythical beings which have been replaced by a remarkable collection of gods, angels, spirits, ghosts (i.e., the "Holy Ghost, a Person distinct from the Father and the Son") and other mystical beings in our current religions. Are these spiritual beings merely exercises in human imagination?

Religions may have been invented primarily to explain natural phenomena, stabilize social structure, and "keep the flocks in the fold." It is interesting to note that almost all religious people "inherit" the religion of their family and community. But today, individuals can "choose" a belief system over a scientific system to explain our origins and provide rationalization for preferred behavior and morality.

Let's reflect on the possible consequences of such a choice. Does belief in the supernatural and eternal life prevent some people from participating in solving the immense problems that face us? Does interpretation of religious doctrines prevent others from acting responsibly in society? Faced with current controversies and political atmospheres, we must conclude that these questions can be answered affirmatively. Problems, for example, of global human population growth and global warming are either denied or deemed unimportant. In this regard, as well as many others, religions can be viewed as dangerous forces that mislead us and promote human suffering.

It must be further acknowledged, however, that science has serious weaknesses. There are immense gaps in our knowledge, and some areas of potential research are not likely to be subjected to objective experimentation in the near future. These are truly the areas that still belong to the realm of religion: the unknown. In fact, science will never answer all questions. But people in science, engineering and the creative arts deserve immense credit. They have brought forth concrete progress that can be used for the benefit of all. Science can and should be used to solve our most significant problems.

Imagination created religions when scientific explanations were not available. The mere availability of answers provided people with a sense of security and well being. But now that we do have objectivity, why is it that some religions feel the necessity to suppress scientific facts such as evolution, the importance of human birth control and the need for a reduction in the human population for long-term biosphere preservation and human survival? Do religious leaders feel threatened by science? Are theologians so preoccupied with their dogmas, or with the goal of attaining nirvana, heaven or a favorable reincarnated state, that they find it unnecessary or uninteresting to deal with the major problems facing mankind? In other words, do religious convictions hinder progress? Since religions are rooted in the past and strive to maintain the status quo, we can understand why they do.

Imagination may be essential for problem solving, but it should be used to ensure our common future on Earth and the sanctity of life. It should not be used for destruction and discrimination. Religions that hinder the preservation of our common biosphere or justify inflicting suffering and death upon others cannot be tolerated. A renaissance in imaginative thinking, education and cooperation will be necessary to solve our common problems. In the near future, humans, and humans alone, must solve the immense problems that we have created. Otherwise, the prophesy of "The fire next time" is likely to be fulfilled. But it will not be an act of a god; it will be an act of humankind. 